\title{
Electrochemical Determination of the Herbicide Bentazone Using a Carbon Nanotube $\beta$-Cyclodextrin Modified Electrode
}

\author{
V. Rahemi, J. M. P. J. Garrido, F. Borges, C. M. A. Brett, E. M. P. J. Garrido
}

\begin{abstract}
An electrochemical sensor has been developed for the determination of the herbicide bentazone, based on a GC electrode modified by a combination of multiwalled carbon nanotubes (MWCNT) with $\beta$-cyclodextrin $(\beta$-CD) incorporated in a polyaniline film. The results indicate that the $\beta$-CD/MWCNT modified GC electrode exhibits efficient electrocatalytic oxidation of bentazone with high sensitivity and stability. A cyclic voltammetric method to determine bentazone in phosphate buffer solution at $\mathrm{pH}$ 6.0, was developed, without any previous extraction, clean-up or derivatization steps, in the range of $10-80 \mu \mathrm{mol} \mathrm{L}{ }^{-1}$, with a detection limit of $1.6 \mu \mathrm{mol} \mathrm{L}{ }^{-1}$ in water. The results were compared with those obtained by an established HPLC technique. No statistically significant differences being found between both methods.
\end{abstract}

Keywords: Herbicides, Bentazone, Voltammetric sensors, $\beta$-Cyclodextrin, Carbon nanotubes

\section{Introduction}

Water is one of our most precious resources, essential for life and survival. However, the developmental models adopted by humankind have not taken into account the risks to the environment. The 20th century introduced more than 100000 chemicals that are still being used in our everyday life, in households, industries or agriculture. These chemicals were introduced without realizing the consequences to the environment and, directly or indirectly, to human health $[1,2]$.

The extensive use of pesticides in world-wide agricultural practice has led to contamination of water resources, which is a challenge for the preservation and sustainability of the environment. The pollution of water by pesticides is a topic of considerable environmental interest, owing to the increasing number of pesticides detected in water and to the establishment of strict directives in Europe, aiming at the protection of water sources used for the production of drinking water $[3,4]$.

Bentazone (3-isopropyl-(1H)-2,1,3-benzothiadiazin-4(3H)-one-2,2-dioxide) is a selective, contact herbicide used for post-emergent weed control of broad leafed weeds in beans, rice, maize and peanuts. Bentazone still remains one of the most frequently used herbicides on maize crops in Portugal [5]. Although extensive studies to evaluate the potential carcinogenicity of bentazone indicated the absence of significant tumor increase when chronic and high doses were administered to rats and mice, the concern for human health is still very high. Its low adsorption and high water solubility make bentazone one of the most commonly detected pollutants in the surface waters and groundwaters of Portugal and other European countries [6-9].

Methods that have been reported for the quantification of bentazone in environmental samples include gas chromatography and high performance liquid chromatography (HPLC) [9-13]. Although these methods have been widely applied due to their high sensitivity, selectivity and ability to minimize interferences, these merits are overshadowed by extensive and time-consuming sample preparation, making them unsuitable for routine environmental monitoring.

Electroanalytical techniques have been shown to be very useful in the study of toxic substances, used for disease and pest control, such as pesticides, mainly because of environmental concerns such as the contamination of water resources [14-17]. The use of a bare glassy carbon electrode for the detection of bentazone in commercial samples has already been reported [18]. Extensive adsorption of the products formed during the oxidation of bentazone causes severe poisoning of the bare electrode surface, limiting its use [18]. The use of carbon paste electrode bulk-modified with polyaniline and polypyrrole conducting polymers, and a polymeric film of a manganese 
phthalocyanine complex, formed on a glassy carbon electrode, have also been reported $[19,20]$.

Carbon-nanotubes (CNT) represent an important group of nanomaterials with attractive chemical, electronic, and mechanical properties. Recently, CNTs have been incorporated into electrochemical sensors since they offer unique advantages including enhanced electronic properties, a large edge plane/basal plane ratio, and fast electrode kinetics. Therefore, CNT-based sensors generally have higher sensitivities, lower limits of detection, and faster electron transfer kinetics than traditional carbon electrodes [21]. The insolubility of CNTs in all solvents is considered an important drawback to their use in electrochemical sensors. Several strategies have been proposed to dissolve CNTs including oxidative treatment, polymer wrapping, and sidewall functionalization. Wrapping CNTs in polymeric chains, besides improving the solubility, also maintains the physical properties of the CNTs. and a popular strategy for detection with CNT sensors is to immobilize CNTs onto electrodes using polymer coatings. In recent years, polyaniline (PANI) has aroused much interest, because the conducting polymer film has good transducing properties and high stability and reproducibility. In addition, PANI films are positively charged, which would promote linking with negatively charged substances, for example negatively charged MWCNTs with carboxylate functional groups.

Cyclodextrins (CD) are oligosaccharides composed of six, seven, or eight glucose units $(\alpha, \beta$, or $\gamma$-CD, respectively) which are toroidal in shape with a hydrophobic inner cavity and a hydrophilic exterior. This structure leads to the formation of inclusion complexes with a variety of guest molecules that fit inside the torus-shaped cavities, which serve as host sites. Electrodes modified with multiwalled CNT (MWCNT) in which $\beta$-CD are incorporated have recently been successfully used to study and quantify many organic molecules owing to the excellent properties of both materials [22-24].

In this work, we report a novel strategy based on the simultaneous modification of a glassy carbon electrode with a polyaniline-CNT cyclodextrin film (PANI- $\beta-\mathrm{CD} /$ MWCNT) for the determination of bentazone herbicide. The chemical recognition of bentazone by $\mathrm{CD}$ is combined with the added advantage of a faster electron transfer process due to the negatively-charged carboxylate functionalized MWCNT, dispersed in the conducting PANI matrix. The modified electrode developed was employed for the direct oxidative determination of bentazone in pure and natural water samples by cyclic voltammetry.

\section{Experimental}

\subsection{Reagents}

Multiwalled carbon nanotubes (MWCNTs) were obtained from NanoLab (USA). Bentazone, aniline and $\beta$-cyclodextrin $(\beta-\mathrm{CD})$ were supplied by Sigma-Aldrich Química
(Sintra, Portugal). Analytical grade reagents purchased from Merck (Darmstadt, Germany) were used without additional purification.

Double distilled deionized water was used throughout the experiments. Buffer solutions employed for voltammetric determinations were $0.1 \mathrm{molL}^{-1}$ in the $\mathrm{pH}$ range 3-9.

HPLC-grade methanol was obtained from Carlo Erba. Prior to use, the solvents were filtered through a $0.45 \mu \mathrm{m}$ filter.

\subsection{Apparatus}

Voltammetric experiments were performed using an $\mathrm{Au}-$ tolab PGSTAT 12 potentiostat/galvanostat (Metrohm Autolab, Netherlands) in a one-compartment glass electrochemical cell equipped with a three-electrode system consisting of a bare or modified glassy carbon working electrode (GCE, $d=2 \mathrm{~mm}$ ), a platinum wire counter electrode and an $\mathrm{Ag} / \mathrm{AgCl}$ (saturated $\mathrm{KCl}$ ) reference electrode. All measurements were carried out at room temperature.

A Crison $\mathrm{pH}$-meter with glass electrode was used for $\mathrm{pH}$ measurements (Crison, Spain).

The HPLC method for the determination of bentazone [12] was carried out using a HPLC/DAD system consisting of a Shimadzu instrument (pump model LC-20AD, Tokyo, Japan), equipped with a commercially prepacked Nucleosil 100-5 C18, analytical column $(250 \mathrm{~mm} \times 4.6 \mathrm{~mm}$, $5 \mu \mathrm{m}$, Macherey-Nagel, Düren, Germany) and UV detection (SPD-M20A) at the wavelength maximum determined by the analysis of the UV spectrum $(230 \mathrm{~nm})$. The mobile phase consisted of methanol-water $(60: 40, \mathrm{v} / \mathrm{v})$, adjusted to $\mathrm{pH} 4.6$ with phosphoric acid. It was delivered isocratically at $0.8 \mathrm{~mL} \mathrm{~min}^{-1}$ at room temperature. The chromatographic data were processed in a Samsung computer, fitted with LabSolutions software (Shimadzu, Japan).

\subsection{Preparation of Modified Electrochemical Sensors}

MWCNT-modified electrodes incorporating $\beta$-cyclodextrin $(\beta-C D)$ were prepared and characterized according to a previously reported procedure [24]. Briefly, a mass of $120 \mathrm{mg}$ of MWCNT was stirred in $10 \mathrm{~mL}$ of a $5 \mathrm{~mol} \mathrm{~L}^{-1}$ nitric acid solution for $20 \mathrm{~h}$. The solid product was collected on a filter paper and washed several times with double-distilled water until the filtrate solution became neutral $(\mathrm{pH} \approx 7)$. The functionalized MWCNTs (fMWCNT) obtained were then dried in an oven at $80^{\circ} \mathrm{C}$ for $24 \mathrm{~h}$. Two milligrams of MWCNTs or fMWCNTs were dispersed by using ultrasonic agitation in $1 \mathrm{~mL}$ aqueous $\beta$-CD solution $(2 \%)$ to give a $2 \mathrm{mg} \mathrm{mL}^{-1}$ black suspension.

Prior to use, the $2 \mathrm{~mm}$ GC working electrode was carefully polished with an aqueous slurry of alumina powder (BDH) on a microcloth pad and then thoroughly washed with double-distilled water. After this, the electrode was 
placed first in ethanol and afterwards in double-distilled water, in each case being subjected to sonication to remove traces of alumina and possible contaminants. The clean GCE was then immersed in a solution containing $0.011 \mathrm{~mol} \mathrm{~L}^{-1}$ aniline and $0.025 \mathrm{~mol} \mathrm{~L}^{-1} \mathrm{H}_{2} \mathrm{SO}_{4}$ and the potential was swept between $-0.1 \mathrm{~V}$ and $1.0 \mathrm{~V}$ vs. $\mathrm{Ag} / \mathrm{AgCl}$ at a scan rate of $50 \mathrm{mV} \mathrm{s}^{-1}$ for 50 cycles. After preparation of the polyaniline film on the GC electrode surface, an aliquot of $6 \mu \mathrm{L}$ of the $2 \mathrm{mg} \mathrm{mL}^{-1}$ suspension of MWCNTs or fMWCNTs was dropped onto the electrode surface and dried in air at room temperature.

\subsection{Analytical Procedure}

The PANI- $\beta-C D / f M W C N T$ film coated GC sensor was first activated in phosphate buffer ( $\mathrm{pH} 6)$ by cyclic voltammetric sweeps between +0.5 and $+1.3 \mathrm{~V}$ vs. $\mathrm{Ag} / \mathrm{AgCl}$ until stable cyclic voltammograms were obtained. Accurate volumes of the stock standard solution of bentazone $(10 \mathrm{mM})$ were then added to the voltammetric cell and CVs were recorded from 0.5 to $1.3 \mathrm{~V}$ at a scan rate of $20 \mathrm{mV} \mathrm{s}^{-1}$. The same procedure was applied for the analysis of natural water samples. After each measurement, the PANI- $\beta-C D / f M W C N T$ film coated GC sensor was cleaned by successive cyclic voltammetric sweeps in $0.1 \mathrm{molL}^{-1}$ phosphate buffer $(\mathrm{pH} 6)$ solution until unchanged cyclic voltammograms were obtained (usually after six cycles).

\subsection{Sample Preparation}

A water sample from Leça river (a polluted river with a high content of organic components) was collected in $2.5 \mathrm{~L}$ brown glass bottles. Immediately after arrival in the laboratory, the samples were filtered through $1 \mu \mathrm{m}$ glass fiber filters and $0.45 \mu \mathrm{m}$ cellulose acetate filters, sequentially, to remove suspended particles.

\subsection{Analysis of Bentazone in Water Samples}

Stock standard solutions of bentazone $(10 \mathrm{mM})$ were prepared in ethanol. For calibration curves, standard solutions were prepared in the voltammetric cell by adding accurate volumes of stock standard solution of bentazone to the selected phosphate buffer $\mathrm{pH} 6$ supporting electrolyte in order to obtain concentrations between 10 and $80 \mu \mathrm{M}$. The calibration curve for CV analysis was constructed by plotting the peak current against bentazone concentration $(10,20,40,60$ and $80 \mu \mathrm{M})$.

The limit of detection ( $L O D)$ was calculated according to IUPAC recommendations [25], using a $\mathrm{S} / \mathrm{N}$ ratio of three. Method precision was checked on different days, within day $(n=5)$ and between days $(n=5)$ for three different concentrations. The accuracy of the proposed method was determined by recovery assays and by comparing the results with those obtained from a previously published HPLC method [12]. Recovery assays were carried out at different concentrations by adding known amounts of standard solution of bentazone to the river water samples. The final concentrations of bentazone, after this addition, were 10,40 and $80 \mu \mathrm{M}$.

\section{Results and Discussion}

\subsection{Cyclic Voltammetric Behavior of Bentazone at PANI- $\beta$-CD/MWCNT GC Electrode}

Previous reports have already discussed the interfacial architecture and electrochemical activity of CNT-modified electrodes after incorporating CDs and the resulting recognition effects [23].

Cyclic voltammetry was employed for investigation of the electrochemical properties of bentazone at the modified electrodes. The potential was scanned from +0.5 to $+1.3 \mathrm{~V}$ vs. $\mathrm{Ag} / \mathrm{AgCl}$ in $0.1 \mathrm{~mol} \mathrm{~L}^{-1}$ phosphate buffer solution ( $\mathrm{pH} 6.0$ ), containing $60 \mu \mathrm{M}$ of bentazone. Figure 1 depicts the $\mathrm{CV}$ response obtained using a scan rate of $20 \mathrm{mVs}^{-1}$ at a bare $\mathrm{GC}$ electrode (curve A), at PANI/ MWCNT (curve B), at PANI- $\beta$-CD/MWCNT (curve $\mathrm{C}$ ) and PANI- $\beta-C D / f M W C N T$ (curve D). Apart from the bare GC electrode, where only one oxidation wave is seen, the results for the three types of modified electrode tested show the existence of two anodic peaks, in the potential range studied. No corresponding reduction on scan reversal is observed for any of the cases, which suggests that the electrochemical oxidation occurring is a totally irreversible process. The appearance of the two waves may be interpreted by assuming that the electrochemical oxidation of bentazone takes place on the modified electrodes by electron transfer from both free and adsorbed forms. The free form corresponds to the first peak whereas the strongly adsorbed form is oxidized at a more positive potential. The occurrence of adsorption has also been

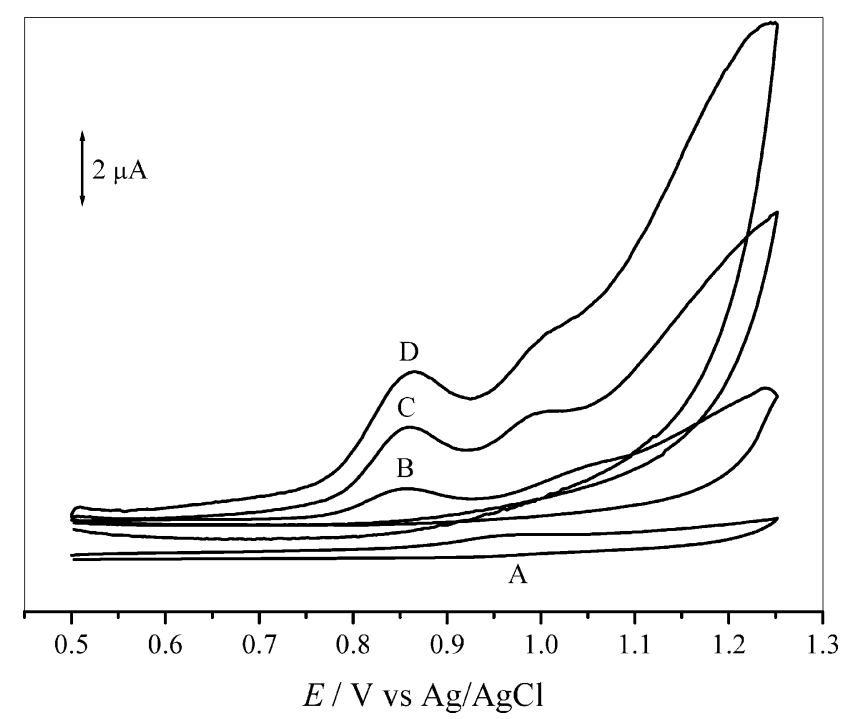

Fig. 1. Cyclic voltammograms of $60 \mu \mathrm{M}$ solutions of bentazone at (A) GCE, (B) PANI/MWCNT/GCE, (C) PANI- $\beta-\mathrm{CD} /$ MWCNT/GCE and (D) PANI- $\beta$-CD/fMWCNT/GCE in $\mathrm{pH} 6$ phosphate buffer electrolyte. Scan rate: $20 \mathrm{mV} \mathrm{s}^{-1}$. 
described in a previous voltammetric study of bentazone [18]. This issue will be discussed more extensively below.

The voltammetric signal obtained for bentazone at the bare GC electrode is rather ill-defined (curve A), with a broad, small anodic wave occurring at $0.98 \mathrm{~V}$. When the GC surface was coated with the PANI/MWCNT film the electrode response to bentazone improved significantly, occurring at a potential less positive by $130 \mathrm{mV}$, with a corresponding increase in the peak current (curve B). This can be attributed to the electrocatalytic effect of PANI/MWCNT and the higher available surface area of the PANI/MWCNT film. The further addition of $\beta$-CD to PANI/MWCNT modified GC electrodes led to a significant increase in the peak currents (curves $C$ and $D$ ), the peak potential remaining the same. The increase of the current for PANI- $\beta$-CD/MWCNT modified GC electrodes compared to bare GC and PANI/MWCNT can be ascribed to the formation of an inclusion complex between $\beta-\mathrm{CD}$ and bentazone [26]. This complexation of bentazone with $\beta$-cyclodextrin has been previously described and the value for the association constant $\left(K_{\mathrm{a}}\right)$, obtained by differential pulse voltammetry, was $118 \mathrm{M}^{-1}$ [26]. The bentazone- $\beta-C D$ complex in the PANI- $\beta-C D / M W C N T$ film then dissociates and bentazone reacts on the MWCNT and also diffuses through the porous layer of MWCNT to the GC surface, increasing the amount of bentazone oxidized. The use of functionalized MWCNTs enhanced the peak current slightly, which can be related to the increase of the surface-active area of the carbon nanotubes (curve D), and, more importantly, considerably reduced bentazone adsorption and consequent poisoning of the sensor surface.

\subsection{Influence of pH and Scan Rate}

The influence of the $\mathrm{pH}$ of the buffer solution on the electrode reaction was examined by cyclic voltammetry in electrolytes with different $\mathrm{pH}$, illustrated for PANI- $\beta-\mathrm{CD} /$

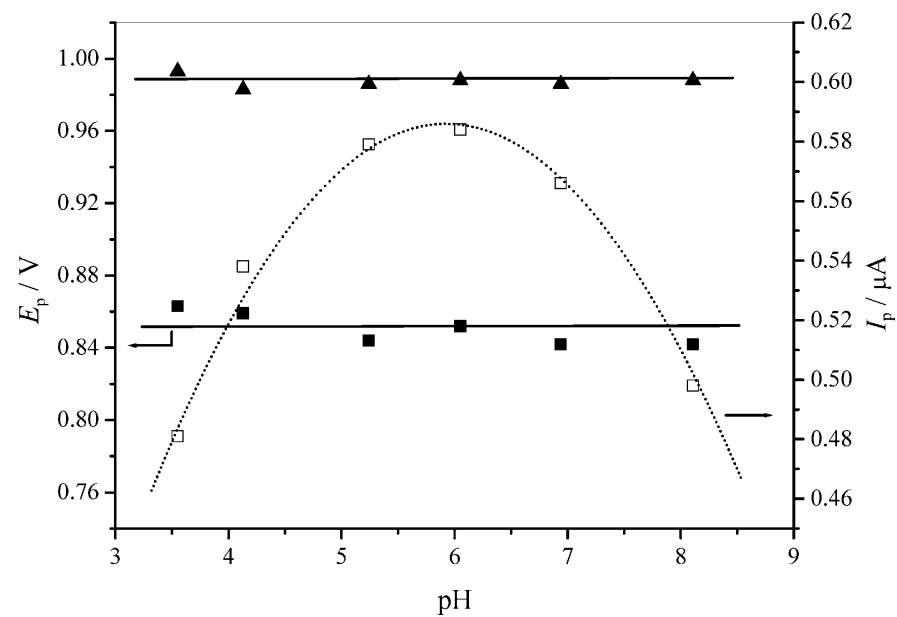

Fig. 2. Plots of $E_{\mathrm{p}}$ (filled symbols) and $I_{\mathrm{p}}$ (open symbols) vs. pH from cyclic voltammograms of $0.1 \mathrm{mM}$ solutions of bentazone at PANI- $\beta$-CD/fMWCNT film electrode in different buffer electrolytes as a function of pH. ( $\square, \square)$ first peak; (ム) second peak. Scan rate: $20 \mathrm{mV} \mathrm{s}^{-1}$.

fMWCNT (Figure 2). A plot of $E_{\mathrm{p}}$ vs. pH shows that the peak potential, for both peaks, is independent of $\mathrm{pH}$ in the interval from 3.6 to 8.1. This was expected considering that bentazone presents keto-enol tautomerism and is a weak acid with a $\mathrm{p} K_{\mathrm{a}}$ of 3.3 (Scheme 1) [27,28]. Thus, it exists predominantly in anionic form under the $\mathrm{pH}$ conditions tested; at $\mathrm{pH} 4$ the anionic form accounts for $83 \mathrm{~mol} \%$ and at $\mathrm{pH} \mathrm{6-7} \mathrm{it} \mathrm{represents} \mathrm{more} \mathrm{than} 99 \mathrm{~mol} \%$. The fact that bentazone exists predominantly in the anionic form supports the hypothesis that the second peak observed using the modified electrodes is due to the adsorbed form of bentazone. Actually, the peak current for the second wave using the PANI- $\beta$-CD/fMWCNT film is less than that obtained using non-functionalized MWCNTs. The decrease of the amount adsorbed suggests a weaker surface interaction of the fMWCNTs with the<smiles>CC=CC=C1Nc2ccccc2C(=O)N1C(C)C</smiles>

Scheme 1. Molecular structure of bentazone, keto-enol tautomerism and dissociation equilibrium [27]. 
deprotonated bentazone. Such a behavior can be explained considering that the negatively charged $-\mathrm{COO}^{-}$ groups existing at the ends or at the sidewall defects of the nanotube structure of functionalized carbon nanotubes [24] repel the bentazone anions, thereby reducing their access to the fMWCNT surface. A similar tendency was reported for the adsorption and electrosorption of bentazone on activated carbon cloth in aqueous solutions [29]. Analyzing the data obtained and those reported in the literature it is plausible that the bentazone oxidation process proceeds at the nitrogen of the tertiary amine $[18,20]$. The higher electron density of the lone pair of the nitrogen of the tertiary amine group makes it susceptible to oxidation, meaning that it is likely that the reaction mechanism corresponds to a fast one-electron transfer followed by a slow chemical step, probably a dimerization of the oxidation product $[18,20]$.

The effect of electrolyte $\mathrm{pH}$ on the peak current was also investigated. A plot of $I_{\mathrm{p}} \mathrm{vs}$. $\mathrm{pH}$ indicates that the peak current reaches a maximum around $\mathrm{pH} 6$ (Figure 2). Therefore, this buffer was chosen for subsequent analytical experiments.

The influence of the scan rate on the peak current of bentazone was investigated in $\mathrm{pH} 6$ phosphate buffer solution. For the first wave, the peak current increases linearly with the square root of the scan rate, in the range $10-130 \mathrm{mV} \mathrm{s}^{-1}$, according to the equation $I(\mu \mathrm{A})=0.160$ $v^{1 / 2}+0.04$ with a linear correlation coefficient of 0.998 (Figure $3 \mathrm{~A}$ ). For the second peak, the anodic peak current is proportional to the scan rate in the range from 10 to $130 \mathrm{mV} \mathrm{s}^{-1}$; the linear regression equation is $I(\mu \mathrm{A})=$ $0.0163 v+0.03$ with a correlation coefficient of 0.996 (Figure $3 \mathrm{~B}$ ). Therefore, the oxidation of bentazone at the PANI- $\beta$-CD/fMWCNT film-modified electrode occurs both by a diffusion-controlled (first peak) and an adsorption-controlled process (second peak).

The data above and similar data for the other modified electrodes support the previously-expressed idea that the electrochemical oxidation of bentazone takes place on the modified electrodes by electron transfer from both free and adsorbed forms.

\subsection{Analytical Application}

$\mathrm{CV}$ experiments were performed in triplicate using the optimized experimental parameters to construct an analytical curve for the determination of bentazone at the PANI- $\beta$-CD/fMWCNT film electrode.

Cyclic voltammograms recorded with increasing amounts of bentazone (10 to $80 \mu \mathrm{M})$ showed that the peak currents increased linearly with increasing concentration (Figure 4). The linear regression equation, $I_{\mathrm{p}}$ $(\mu \mathrm{A})=0.0154 c-0.0032$, where $c$ is the concentration of bentazone in $\mu \mathrm{M}$, can be established with a correlation coefficient of 0.997 (Figure 4 Inset). The limit of detection $(L O D)$, obtained from five runs, was $1.6 \mu \mathrm{M}$. The precision of the method was evaluated by repeatedly $(n=5)$ measuring bentazone, at three concentrations (10, 40 and
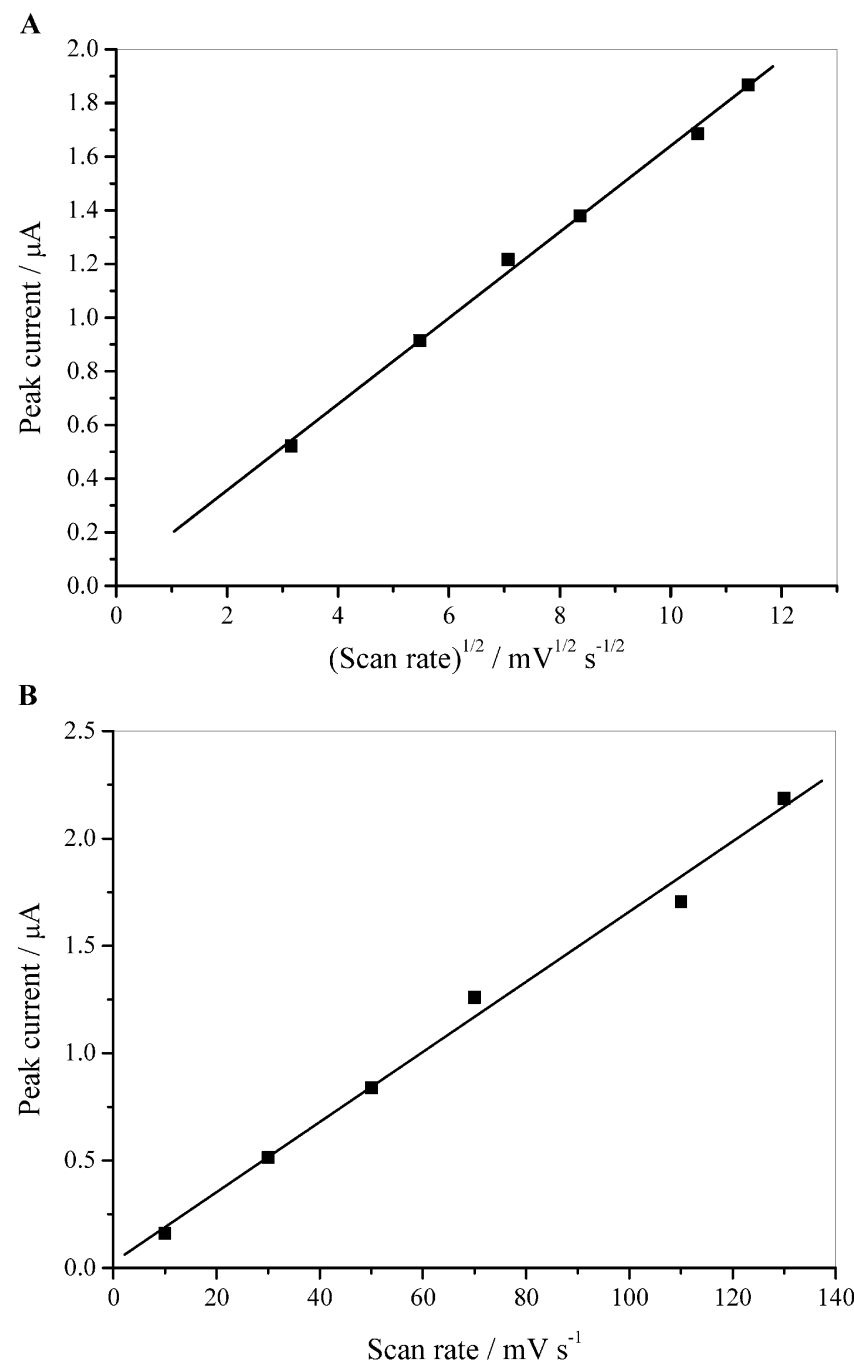

Fig. 3. Plots of scan rate $\left(10,30,50,70,110\right.$ and $\left.130 \mathrm{mVs}^{-1}\right)$ dependence of (A) first and (B) second anodic peaks of bentazone at PANI- $\beta$-CD/fMWCNT film electrode in $\mathrm{pH} 6$ phosphate buffer electrolyte.

$80 \mu \mathrm{M})$ on the same day and over five consecutive days. The maximum value of the inter-day precision obtained, expressed as coefficient of variation, was approximately $2.9 \%$.

The proposed method was applied to the analysis of river water spiked with bentazone, using the standard addition method, in order to eliminate any matrix effects. For this purpose, a water sample was spiked with bentazone in order to achieve final concentrations of 10,40 and $80 \mu \mathrm{mol} \mathrm{L}^{-1}$. The recoveries obtained were close to $100 \%$, as shown in Table 1 .

The accuracy of the proposed voltammetric method was assessed by comparing the results found with those obtained using a previously-published chromatographic procedure [12]. Five independent measurements were carried out, for both the CV and HPLC methods. These results, summarized in Table 1, show that the data from the CV method agree well with those from chromatography. The $F$ - and $t$-test were carried out on the data and 


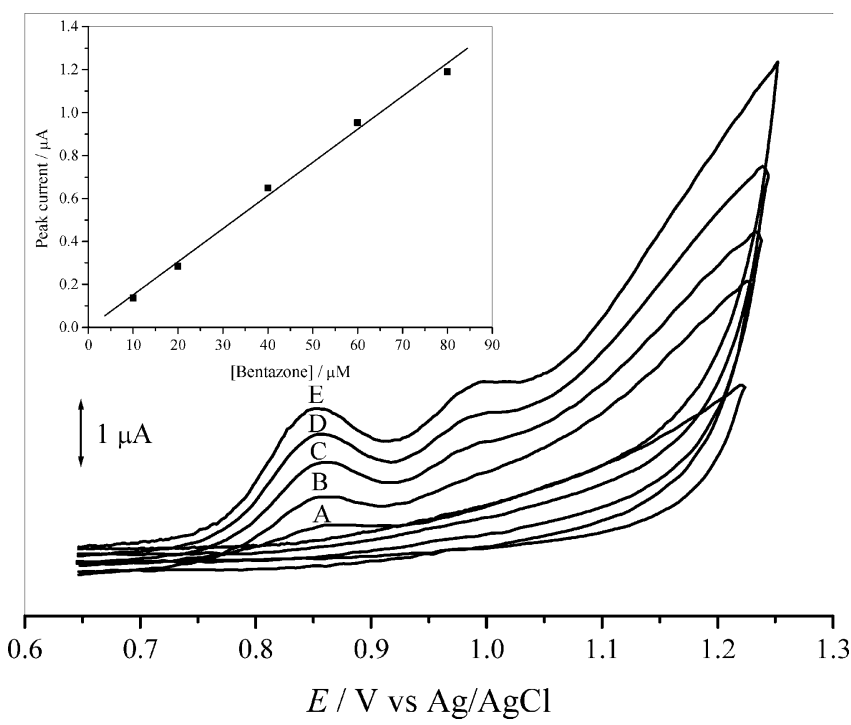

Fig. 4. Cyclic voltammograms of bentazone standard solutions with concentrations of: (A) 10, (B) 20, (C) 40, (D) 60 and (E) $80 \mu \mathrm{M}$ at PANI- $\beta-\mathrm{CD} / \mathrm{fMWCNT}$ film electrode in $\mathrm{pH} 6$ phosphate buffer electrolyte. Inset: Plot of the peak current as a function of bentazone concentration. Scan rate: $20 \mathrm{mV} \mathrm{s}^{-1}$.

the validity of the results obtained was statistically examined. At a confidence level of $95 \%$, the values from the $t$ and $F$-tests were less than the theoretical values, showing that there is no significant difference between the proposed CV technique and the HPLC method. Both methodologies have comparable precision and accuracy. However, the PANI- $\beta$-CD/fMWCNT film electrode proposed here shows a significant improvement in terms of simple preparation and low cost.

The analytical performance of the PANI- $\beta-\mathrm{CD} /$ fMWCNT sensor presented is better than that reported for the determination of bentazone using a bare glassy carbon electrode [18]. The method based on a bare GC electrode showed a higher detection limit, $10 \mu \mathrm{M}$, and a narrower linear range, $15.1-22.6 \mu \mathrm{M}$, than that obtained in the present study. A polymeric film of a new manganese phthalocyanine complex octa-substituted with 2-diethylaminoethanethiol [20] had an analytical sensitivity of $0.288 \mu \mathrm{Acm}^{-2} \mu \mathrm{M}^{-1}$, higher than the $0.106 \mu \mathrm{Acm}^{-2} \mu \mathrm{M}^{-1}$ found here using the PANI- $\beta$-CD/fMWCNT film electrode. However, for the PANI- $\beta$-CD/fMWCNT film electrode, good reproducibility and simple instrumentation, preparation and analytical procedure are important advantages.

\subsection{Operational Lifetime and Selectivity}

The stability of the PANI- $\beta-\mathrm{CD} / \mathrm{fMWCNT/GC}$ modified electrode was tested over a 5-day period. Cyclic voltammetry of bentazone at the modified electrode showed that the oxidation peak potential remained unchanged, and the initial anodic peak current was maintained during this period, with a relative standard deviation lower than $4 \%$.

The influence of various substances as compounds that can potentially interfere with the determination of bentazone was studied. As interfering species, some ions (e.g. $\mathrm{Ca}^{2+}, \mathrm{Mg}^{2+}, \mathrm{NO}_{3}{ }^{-}, \mathrm{PO}_{4}{ }^{3-}$ ) and other herbicides commonly found in plant protection products containing bentazone, i.e. terbuthylazine and dicamba, were selected. Using a bentazone:interferent mass ratio of $1: 1$, no significant interferences were observed (signal change less than $5 \%$ ) from any of these compounds.

\section{Conclusions}

A new electroanalytical procedure is proposed for monitoring the herbicide bentazone in natural waters, based on the use of a PANI- $\beta-\mathrm{CD} / \mathrm{fMWCNT/GC}$ modified electrode. The electrochemical sensor developed showed good electrochemical characteristics and analytical performance. The results show that the new method is sensitive and does not lead to statistically significant differences compared to established HPLC methodology.

The PANI- $\beta-C D / f M W C N T / G C$ film showed electrocatalytic behavior towards the herbicide bentazone, and enabled its determination in polluted river water with excellent selectivity and sensitivity, not requiring separations, clean-up or derivatization steps, which are indispensable in a number of other analytical methodologies.

The combination of host-guest electrostatic interactions with the catalytic and electronic properties of MWCNT embody a new approach towards constructing electrodes for environmental monitoring, with application to the reliable determination of herbicide residues demonstrated.

Table 1. Results obtained for the analysis of bentazone in river water samples using the proposed cyclic voltammetric method and HPLC.

\begin{tabular}{lllllll}
\hline Method & Bentazone added $(\mu \mathrm{M})$ & Bentazone found $(\mu \mathrm{M})[\mathrm{a}]$ & Recovery $(\%)$ & $R S D(\%)$ & $t$-test $[\mathrm{b}]$ & $F$-test $[\mathrm{b}]$ \\
\hline $\mathrm{CV}$ & 10 & 10.3 & 103.0 & 3.2 & 1.98 & 1.48 \\
& 40 & 39.8 & 99.5 & 1.8 & 1.34 & 1.17 \\
\multirow{2}{*}{ HPLC } & 80 & 78.9 & 98.6 & 2.6 & 0.16 & 1.54 \\
& 40 & 9.7 & 97.0 & 2.8 & & \\
& 80 & 40.8 & 102.0 & 1.9 & & \\
\end{tabular}

[a] Average of five replicate measurements. [b] Tabulated $t$ - and $F$-values, at $P=0.05$, are 2.31 and 6.39, respectively. 


\section{Acknowledgements}

Financial support from Fundação para a Ciência e Tecnologia FCT/MCTES Project PTDC/AGR-AAM/105044/ 2008, National Funds PIDDAC also co-financed by the European Community Fund FEDER through COMPETE-Programa Operacional Factores de Competitividade (POFC), is gratefully acknowledged.

\section{References}

[1] M. W. Aktar, D. Sengupta, A. Chowdhury, Interdisc. Toxicol. 2009, 2, 1.

[2] H. Imran, K. A. Dilshad, in Pesticides - The Impacts of Pesticide Exposure (Ed: M. Stoytcheva), InTech, Rijeka, Croatia 2011, pp. 155-178.

[3] European Commission, Directive 2000/60/EC of the European Parliament and of the Council of 23 October 2000 establishing a framework for Community action in the field of water policy, Official Journal of the European Communities, L 327 of 22.12.2000.

[4] D. J. Hamilton, Á. Ambrus, R. M. Dieterle, A. S. Felsot, C. A. Harris, P. T. Holland, A. Katayama, N. Kurihara, J. Linders, J. Unsworth, S.-S. Wong, Pure Appl. Chem. 2003, $75,1123$.

[5] Eurostat, The use of plant protection products in the European Union: Data 1992-2003, Office for official publications of the European Communities, Luxembourg 2007.

[6] H. W. Spencer, Toxicological review of bentazone. Technical report, Environmental Protection Agency, Washington, DC, USA 1998.

[7] Environmental Protection Agency, Bentazone (Basagran) Pesticide Tolerance 2/00. Final rule, Washington, DC, USA 2000.

[8] M. J. Cerejeira, P. Viana, S. Batista, T. Pereira, E. Silva, M. J. Valério, A. Silva, M. Ferreira, A. M. Silva-Fernandes, Water Res. 2003, 37, 1055.

[9] M. Ricart, H. Guasch, D. Barceló, R. Brix, M. H. Conceição, A. Geiszinger, M. J. López de Alda, J. C. López-Doval,
I. Muñoz, C. Postigo, A. M. Romaní, M. Villagrasa, S. Sabater, J. Hydrol. 2010, 383, 52.

[10] K. Kadokami, M. Morimoto, K. Haraguchi, M. Koga, R. Shinohara, Anal. Sci. 1991, 7, 247.

[11] G. Durand, V. Bouvot, D. Barceló, J. Chromatogr. A 1992, 607, 319.

[12] G. M. F. Pinto, I. S. F. Jardim, J. Chromatogr. A 1999, 846, 369.

[13] M. Kuster, M. J. López de Alda, C. Barata, D. Raldúa, D. Barceló, Talanta 2008, 75, 390.

[14] W. F. Smyth, M. R. Smyth, Pure Appl. Chem. 1987, 59, 245.

[15] Electrochemistry for Environmental Protection (Eds: K. Stulik, R. Kalvoda), UNESCO Venice Office, Regional Office for Science and Technology for Europe (ROSTE), Venice, Italy 1996.

[16] E. M. Garrido, C. Delerue-Matos, J. L. F. C. Lima, A. M. Oliveira Brett, Anal. Lett. 2004, 37, 1755.

[17] C. M. P. Vaz, P. R. V. Silva Jr., I. Prado, G. M. Castanho, F. R. Simões, S. A. S Machado, Quim. Nova 2008, 31, 1310.

[18] E. M. Garrido, J. L. Costa Lima, C. M. Delerue-Matos, A. M. Oliveira Brett, Talanta 1998, 46, 1131.

[19] F. R. Simões, L. H. C. Mattoso, C. M. P. Vaz, Sens. Lett. 2006, 4, 319.

[20] I. A. Akinbulu, T. Nyokong, Electrochim. Acta 2009, 55, 37.

[21] C. B. Jacobs, M. J. Peairs, B. J. Venton, Anal. Chim. Acta 2010, 662, 105

[22] Z. Wang, S. Xiao, Y. Chen, J. Electroanal. Chem. 2006, 589, 237.

[23] Q. Shen, X. Wang, J. Electroanal. Chem. 2009, 632, 149.

[24] V. Rahemi, J. J. Vandamme, J. M. P. J. Garrido, F. Borges, C. M. A. Brett, E. M. P. J. Garrido, Talanta 2012, 99, 288.

[25] J. Mocak, A. M. Bond, S. Mitchell, G. Scollary, Pure Appl. Chem. 1997, 69, 297.

[26] C. Yañez, M. Araya, S. Bollo, J. Incl. Phenom. Macrocycl. Chem. 2010, 68, 237.

[27] K. Peter, C. Volhardt, N. E. Schore, in Organic Chemistry: Structure and Function, Freeman, New York 1999.

[28] C. D. S. Tomlin, The e-Pesticide Manual, 12th ed. CD-ROM form, Version 2.0, British Crop Protection Council, Hampshire, UK 2001.

[29] C. O. Ania, F. Béguin, Water Res. 2007, 41, 3372. 